\title{
John Howship (1781-1841) and growing skull fracture: historical perspective
}

\author{
Shyamal C. Bir, MD, PhD, Piyush Kalakoti, MD, Christina Notarianni, MD, and \\ Anil Nanda, MD, MPH \\ Department of Neurosurgery, LSU Health Shreveport, Louisiana
}

\begin{abstract}
In the late 18th and early 19th centuries, Dr. John Howship, a pioneering British surgeon, described the clinical features and pathophysiology of various surgical disorders of the human body. His critical contributions to pediatric neurosurgery came in 1816 when he first described the features of an important childhood condition following head trauma, what he referred to as parietal bone absorption. This condition as depicted by Dr. Howship was soon to be christened by later scholars as traumatic cephalhydrocele, traumatic meningocele, leptomeningeal cyst, meningocele spuria, fibrosing osteitis, cerebrocranial erosion, and growing skull fracture. Nevertheless, the basic features of the condition as observed by Dr. Howship were virtually identical to the characteristics of the above-mentioned disorders. This article describes the life and accomplishments of Dr. Howship and his contributions to the current understanding of growing skull fracture. http://thejns.org/doi/abs/10.3171/2014.12.PEDS14484
\end{abstract}

KEY WORDS John Howship; growing skull fracture; historical perspective

$\mathrm{G}$ ROWING skull fracture (GSF) is a rare but significant late complication following head trauma. It accounts for $0.05 \%-1.6 \%$ of all childhood fractures $^{6,13}$ and occurs almost exclusively in children under 3 years of age in whom the diastasis is greater than 3-4 mm. ${ }^{4,8,12,22,27,28}$ A GSF may remain undetected during the first few years of life. It has been described as a leptomeningeal cyst herniation through a dural tear without evidence of increased intracranial pressure, implicating physiological growth and brain cerebrospinal fluid pulsations as causative factors. ${ }^{17}$ Because a delay in diagnosis and/ or improper management can exacerbate this condition, ${ }^{6,16}$ early identification of symptoms and prompt management are critical to achieving a good outcome. Although much is known about this uncommon condition, little is known about the British surgeon, Dr. John Howship, who described GSF for the first time. ${ }^{11}$ Here we review the life and accomplishments of Dr. Howship and his immense contributions to our understanding of GSF.

\section{History}

\section{Biography of John Howship}

John Howship (Fig. 1) was born in London, England, in 1781. Upon entering medical school in 1799, Howship worked as an assistant to Dr. John Heaviside (1748-1828), a distinguished surgeon and museum proprietor. "Museum medicine" of the 19th century focused students' attention on particular anatomical sites of disease dissected out from the rest of the body. Under Heaviside's tutelage, Howship became a skillful dissector, performed autopsies, and collected specimens from his dissections. These activities were considered gentlemanly pursuits in the late 18th century, and many of Howship's specimens are pre-

ABBREVIATION GSF = growing skull fracture.

SUBMITTED September 15, 2014. ACCEPTED December 15, 2014.

INCLUDE WHEN CITING Published online July 17, 2015; DOI: 10.3171/2014.12.PEDS14484.

DISCLOSURE The authors report no conflict of interest concerning the materials or methods used in this study or the findings specified in this paper. 


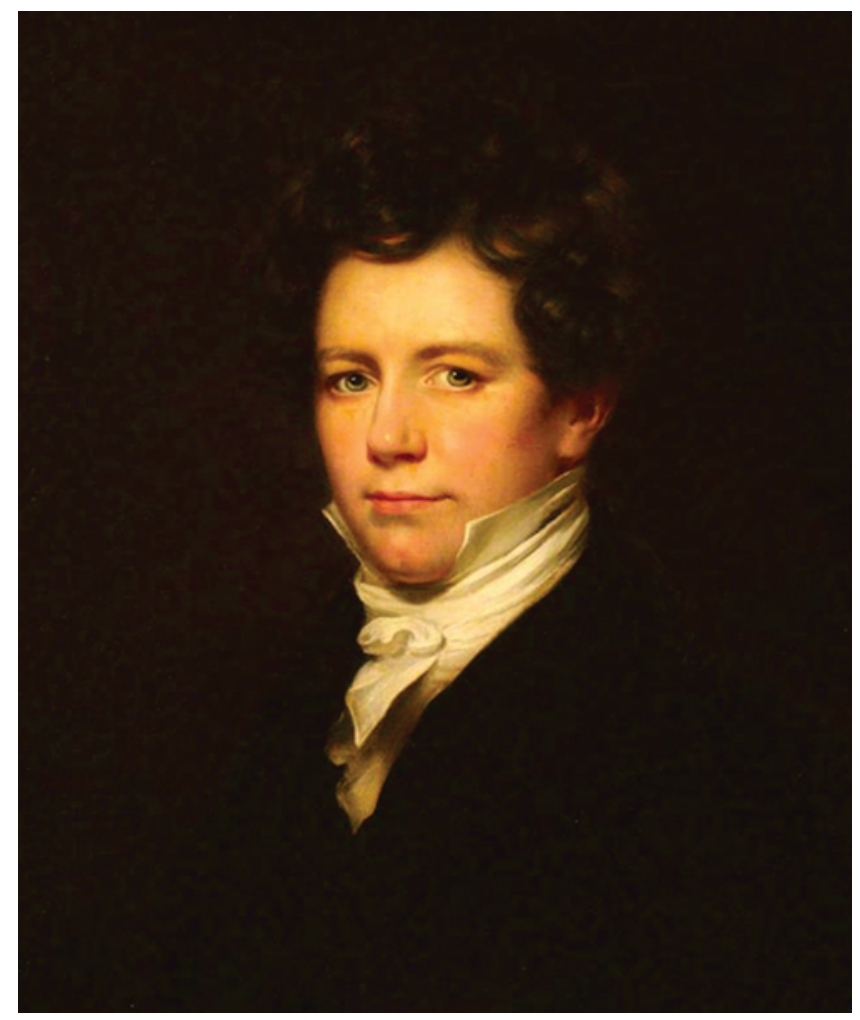

FIG. 1. Portrait of John Howship. Courtesy of the Royal College of Surgeons of England. Figure is available in color online only.

served in the John Heaviside museum (Hanover Square, London) (Fig. 2).

In 1805, Dr. Howship was appointed as an assistant surgeon at the St. George's Infirmary, London, and a lecturer at the school of the St. George's Hospital. In 1834, Dr. Howship moved to the Charing Cross Hospital as an assistant surgeon and was subsequently promoted to chief surgeon in 1836, after his predecessor, Dr. Thomas Joseph Pettigrew (1791-1865), was ousted for demanding and obtaining $£ 500$ from Dr. Howship for the assistant surgeon position. In 1833, Dr. Howship gave the Hunterian Lecture at the College of Surgeons and was a member of the council of the Royal College of Surgeons from 1828 until his death on January 22, 1841, of hemorrhage from an abscess of the lower leg due to a chronic disease of the tibia. By the time of his death, he was one of the most distinguished surgeons in England.

Howship's most noteworthy publication was his book, Practical Observations in Surgery and Morbid Anatomy (Fig. 3), published in 1816. This work contains the preliminary description of what is now known to us as "growing skull fracture." In addition to his observations on GSF, Howship made significant contributions to the understanding of disorders of bone, the gastrointestinal system, and the genitourinary tract. Some of his other notable publications on gastrointestinal diseases are Practical Remarks Upon Indigestion and Practical Observations on the Symptoms (1823), and Practical Observations on the Symptoms, Discrimination, and Treatment of Some of the Most Important Diseases of the Lower Intestines, and

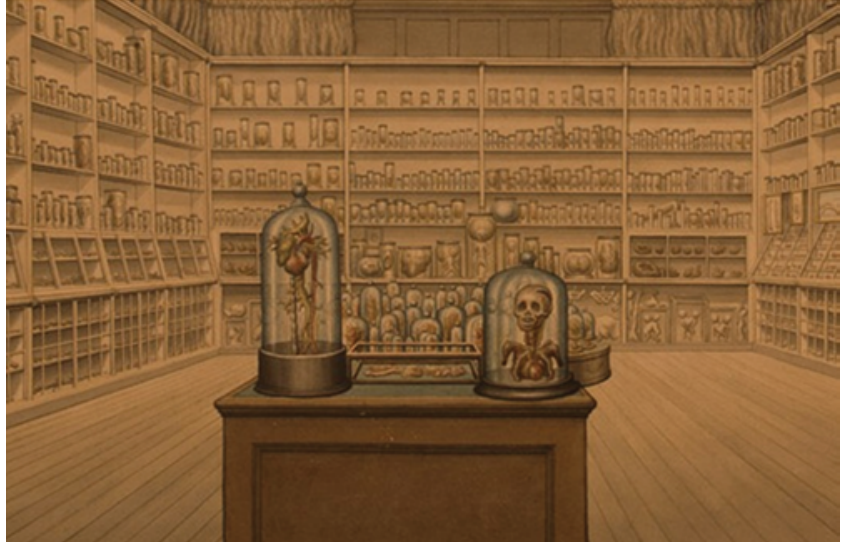

FIG. 2. Interior of John Heaviside's Museum, 1814, watercolor on paper, $41 \times 58 \mathrm{~cm}$, by John Howship. Courtesy of the Royal College of Surgeons of England. Figure is available in color online only.

Anus (1821). In urology he published Practical Observations on the Diseases of the Urinary Organs in 1816. He also described specific signs related to surgical disorders. The Howship-Romberg sign identifies obturator hernia ${ }^{32}$ and the Howship lacuna sign is a groove or pit containing osteoclasts indicative of bone resorption.

\section{Howship and the Idea of the Growing Skull Fracture}

The beginning of our current understanding of GSF dates back to 1816 when Dr. Howship reported in Section 1, Case 10 of Practical Observations in Surgery and Morbid Anatomy, partial absorption of the parietal bone in a 9-month-old female infant after she fell from stairs (Figs. 3 and 4). ${ }^{11}$ The child presented in an unconscious state with a $3 \times 1$-in depressed fracture of the parietal bone. The condition was managed conservatively with leeches for pain management and saturnine lotion, a saturated solution of subacetate of lead consisting of $25 \%$ acid and

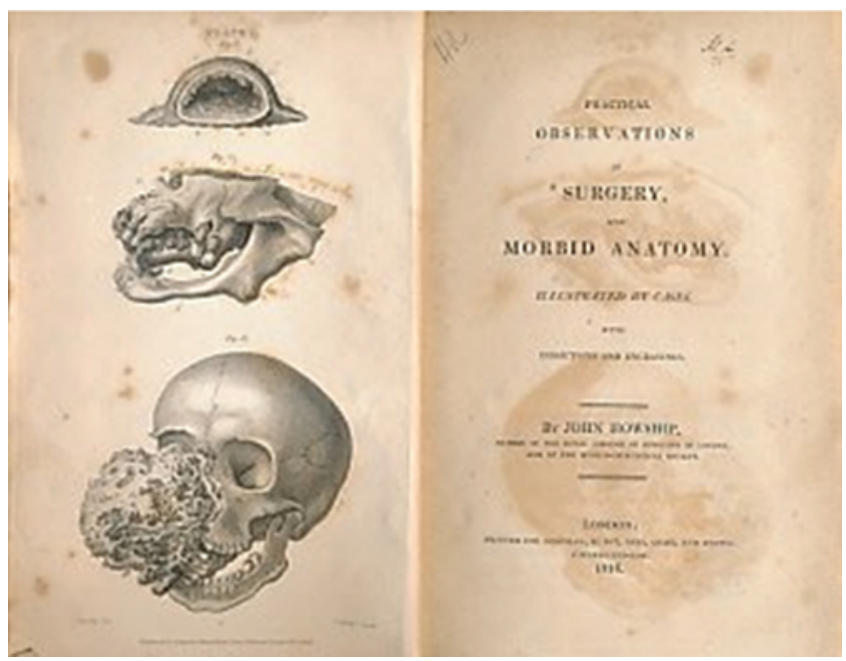

FIG. 3. Cover of Dr. John Howship's publication entitled Practical Observations in Surgery and Morbid Anatomy, which contained the original description of partial absorption of parietal bone, what is now known as growing skull fracture. Public domain. Figure is available in color online only. 


\section{Cass 10. \\ Partial Alborption of the Parietal. Bome, ariaing, froes a Blos: on the Hrad.}

A child at the age of nine months, playing near a flight of stairs, fell down, and was taken up at the bottom in a state of insensibility.

There was no wound upon the head; but on examination, there was a broad line parallel with the coronal suture, where the right parietal bone was depressed for the length of three inches, and the breadth of one inch. At this part, from the form of the depression, it was supposed that the head had struck against the edge of one of the stairs.

The medical gentleman who attended, directed leeches to be applied to the temples, the seat of the injury being kept cool with a saturnine lotion. The infiant remained insensible for a considerable length of time. Within a fortnight after the accident, the mother thought she perceived the pulsations of the brain where the blow had been received, and this in a little time became more decidedly manifest. The child improved, but slowly; and when, after some weeks, sbe had partially recovered some power of motion, it was perceived that the left side was completely paralytic. The insensibility remained, and for the first six weeks there were frequent attacks of convulsion.

Almost four months passed before the child was sufficiently restored to be observant of what passed around her; and long after this she remained exceedingly weak. She was in the third year of her age before she could stand unsupported ; and even then, all the weight was evidently laid upon the right leg. the left having scarcely any power. Subsequent to this period her strength and health gradually improved, but at the age of four years the left side was still deficient, both in heat and strength, while the opening in the cranium remained undiminished. Upon laying the hand on the part, the pulsations of the brain were felt strong and distinct. The feel was much the same through the integuments, as if so much of the skull had been carefully taken out with a saw. The mangin of the opening did not seem thickened, but felt smooth and equal.

The defect was not at this time attended with any material inconvenience, nor productive of pain. Whenever the child coughed or cried, the part became tense, so as to form an evident swelling : but in other respects she seemed to be pretty well recovered.

FIG. 4. Original case report by John Howship, which is taken from his famous book Practical Observations in Surgery and Morbid Anatomy. Courtesy of Bodleian Library, University of Oxford, England. Public domain.

$75 \%$ lead, to keep the injury site cool. Two weeks after the accident, the mother felt pulsations of the brain at the site of injury. Four months after the accident, the child regained consciousness but was weak. Until her 3rd year of life, she could not stand unsupported, and weakness in the left leg persisted. However, her strength and health gradually improved. By age 4, her left leg was still defi- cient in strength and the opening in the cranium remained undiminished. The pulsations of the brain could be felt over the site of injury and were distinct. Upon coughing or crying, the affected site became tense and swollen. On the basis of his observation, Dr. Howship implicated the pathophysiology of what is now known as the GSF to the disruption of blood supply to the fractured bone.

\section{Historical Evolution of Growing Skull Fracture}

Following the first description of GSF by Howship in 1816, ${ }^{11}$ Carl von Rokitansky (1804-1878) provided the first pathological description in Vienna in $1856 .{ }^{24}$ While performing an autopsy on an 8-month-old child, Rokitansky found a fluid-filled sac above and a dural opening and an underlying brain injury below the cranial aperture; this lesion measured $6 \times 4 \mathrm{~cm} .{ }^{24}$ In 1862, Theodor Billroth (1829-1894) first used the term "meningocele spuria" to describe an external sac of CSF in a child who suffered an injury to the cranium via forceps delivery. This "spurious meningocele" progressively enlarged to the size of the head itself. At autopsy, Dr. Billroth noticed an opening in the dura mater corresponding with the cranial defect. ${ }^{2}$ Until that time, the distinguishing feature of GSF was considered to be a collection of CSF exterior to the skull developing after a trauma, and meager, if any, attention was paid to the fractured cranial site..$^{10,15,23}$ Later, Josef Weinlechner (1829-1906) broadened the clinical description by documenting an enlarging cephalhydrocele in a 5-month-old following a fall from height ${ }^{31}$ however, the term "traumatic cephalhydrocele" appeared in the first American series reported in 1884 by Dr. P. S. Conner at the Medical College of Ohio. ${ }^{3}$ Subsequently, Dr. Thomas Smith reported another case of traumatic cephalhydrocele with a pulsatile cranial defect. ${ }^{26}$ In 1885 , Rickman John Godlee (1849-1925) reported on 2 infants in whom pulsating subcutaneous tumors developed after a simple skull fracture. ${ }^{7}$ In the same year, Alexander von Winiwarter (1848-1917) documented a large hiatus in the skull subsequent to head trauma..$^{30}$

The basis of a surgical approach to this condition was established following the 1907 operative report by Sir Charles Ballance (1856-1936), who described a 4-yearold male child who, after a fall from a height of 22 feet, developed a cephalhydrocele, widened fracture, dural defect, and underlying brain injury. ${ }^{1}$ A scalp flap was pulled downward at the site of injury and exposed the herniated brain mass through the fractured parietal bone. The discontinuity in the parietal bone was observed extending obliquely downward and forward from the sagittal suture. The fragment of the parietal bone in front of the fracture was removed by disarticulation of the sagittal and coronal sutures. Similarly, a corresponding fragment of parietal bone posterior to the fracture site was also detached. The breached dural opening was enlarged by incisions made at right angles to the tear and the empty space in the cranium. The flap was then replaced, and the patient eventually made a full recovery 2 years later. ${ }^{1}$ Soon after this, Sir Wilfred Trotter (1872-1939) operated on a patient in whom cystic dilation of the lateral ventricle extended out to the cranial defect. He designated the condition as "traumatic ventricular cyst." The 3 characteristic features 
noted by Trotter were a gap in the skull, associated pulsations, and a history of childhood injury. ${ }^{29} \mathrm{With}$ the advent of the roentgenogram as an aid to diagnosis, Cornelius Dyke (1900-1943) in 1937 first described the radiographic aspects of this condition and labeled it as a "leptomeningeal cyst." 5 The roentgenological diagnosis was based on 3 features: widening of an old fracture, edging of the inner table of the skull, and an accentuated vascularity of the affected bone. In 1940, on the basis of pathological findings of the biopsy materials, H. K. Pancoast et al. ${ }^{19}$ termed this condition "fibrosing osteitis." In 1941, Wilder Penfield and T. C. Erickson used the term "cerebrocranial erosion" to refer to an erosion of the skull overlying dural defects. ${ }^{20}$ Likewise, in 1955 Dr. G. F. Rowbotham referred to traumatic meningocele and described the loss of bone as a traumatic malacia. ${ }^{25}$ However, it was $\mathrm{H}$. W. Pia and $\mathrm{W}$. Tonnis, describing their findings of traumatic cephalhydrocele with enlargement of fracture developing into a hiatus in the skull, who coined the term "growing skull fracture" to describe such conditions. ${ }^{21}$

\section{Modern Concept and Treatment Options for Growing Skull Fracture}

There are currently 2 widely accepted 3 -stage classifications of GSF. ${ }^{14,18}$ The original classification was based on the clinical progression of the disease, ${ }^{18}$ while the more recent classification relies on the radiological features present in the GSF. ${ }^{14}$ In this modern classification, GSF is subdivided into the following 3 subtypes: skull fracture with the presence of a leptomeningeal cyst; skull fracture with underlying, damaged, gliotic brain; and porencephalic cyst extending through the skull defect into the subgaleal space. ${ }^{14}$ Treatment strategies vary depending on the subtype of the GSF. Simple cases with leptomeningeal cyst have been treated with duraplasty and acrylic cranioplasty. ${ }^{14,17,28}$ The possibility of increased intracranial pressure should be evaluated in patients with gliotic brain and/ or a porencephalic cyst. If elevated intracranial pressure is present, this should be managed with the placement of a ventriculoperitoneal shunt. The GSF can then be treated with dural repair and cranioplasty using autologous bone graft or methylmethacrylate. ${ }^{9,14,28}$ Children, especially those under 3 years of age, with linear skull fractures should be followed serially with clinical examination and palpation of the defect, and with radiographic imaging, if needed, to ensure healing of the fracture site. ${ }^{14}$

\section{Conclusions}

With the resources available in the 18th and 19th centuries, John Howship's achievements are nothing short of astonishing. The first depiction of GSF by Howship heralds a significant contribution to the field of pediatric neurosurgery and has helped our current understanding of the disease. He should be recognized in the field of neurosurgery for his contributions to the discovery and management of GSF.

\section{References}

1. Ballance CA: Some Points in the Surgery of the Brain and Its Membranes. London: Macmillan, 1907
2. Billroth T: Ein Fall von Meningocele spuria cum fistula ventriculi cerebri. Arch Klin Chir 3:398-442, 1862

3. Conner P: Traumatic cephalhydrocele: with a report of two cases. Am J Med Sci 88:103-110, 1884

4. Décarie JC, Mercier C: The role of ultrasonography in imaging of paediatric head trauma. Childs Nerv Syst 15:740-742, 1999

5. Dyke CG: The roentgen ray diagnosis and treatment of diseases of the skull and intracranial contents, in Palmer WW (ed): Nelson's Loose-Leaf Medicine. New York: Nelson \& Sons, 1937, Vol 6, pp 185-214

6. Ersahin Y, Gülmen V, Palali I, Mutluer S: Growing skull fractures (craniocerebral erosion). Neurosurg Rev 23:139_ 144,2000

7. Godlee RJ: Two cases of simple fracture of the skull in infants followed by the development of a pulsating subcutaneous tumour. Trans Pathol Soc Lond 36:313-324, 1885

8. Gupta SK, Reddy NM, Khosla VK, Mathuriya SN, Shama BS, Pathak A, et al: Growing skull fractures: a clinical study of 41 patients. Acta Neurochir (Wien) 139:928-932, 1997

9. Halliday AL, Chapman PH, Heros RC: Leptomeningeal cyst resulting from adulthood trauma: case report. Neurosurgery 26:150-153, 1990

10. Haward JW: On a case of fracture of skull, followed by pulsating fluid tumour of scalp, and escape of cerebro-spinal fluid. Lancet 94:79-80, 1869

11. Howship J: Practical Observations in Surgery, and Morbid Anatomy. London: Longman, Hurst, Rees, Orme, and Brown, 1816

12. Lende RA, Erickson TC: Growing skull fractures of childhood. J Neurosurg 18:479-489, 1961

13. Leung GK, Chan KH, Hung KN: Growing skull fracture in an adult nine years after blunt head trauma. J Clin Neurosci 18:855-857, 2011

14. Liu XS, You C, Lu M, Liu JG: Growing skull fracture stages and treatment strategy. J Neurosurg Pediatr 9:670-675, 2012

15. Lucas RC: A case of fracture of the skull, followed by a collection of cerebro-spinal fluid beneath the scalp. Recovery. Guys Hosp Rep 21:363-369, 1876

16. Mihajlović MH, Nikolić IM, Raicević MM: [Growing skull fracture.] Vojnosanit Pregl 63:761-764, 2006 (Serbian)

17. Muhonen MG, Piper JG, Menezes AH: Pathogenesis and treatment of growing skull fractures. Surg Neurol 43:367373, 1995

18. Naim-Ur-Rahman ZJ, Jamjoom Z, Jamjoom A, Murshid WR: Growing skull fractures: classification and management. $\mathbf{B r}$ J Neurosurg 8:667-679, 1994

19. Pancoast HK, Schaeffer JP, Pendergrass EP: The Head and Neck in Roentgen Diagnosis. Springfield, IL: Charles C Thomas, 1940

20. Penfield W, Erickson TC: Epilepsy and Cerebral Localization. A Study of the Mechanism, Treatment and Prevention of Epileptic Seizures. Springfield, IL: Charles C Thomas, 1941

21. Pia HW, Tonnis W: [Growing skull fractures of childhood.] Zentralbl Neurochir 13:1-23, 1953 (Ger)

22. Ramamurthi B, Kalyanaraman S: Rationale for surgery in growing fractures of the skull. J Neurosurg 32:427-430, 1970

23. Reckitt JDT: Fracture of skull; effusion of cerebro-spinal fluid beneath the scalp; aspiration; recovery. Lancet 1:909, 1881

24. Rokitansky CV: Lehrbuch der pathologischen Anatomie, ed 3. Vienna: W. Braumuller, 1856, Vol 2

25. Rowbotham GF: Acute head injuries. Can Serv Med J 11:585-586, 1955

26. Smith T: Traumatic cephalhydrocele. St Barth Hosp Rep 20:233-240, 1884 
27. Tandon PN, Banerji AK, Bhatia R, Goulatia RK: Craniocerebral erosion (growing fracture of the skull in children). Part II. Clinical and radiological observations. Acta Neurochir (Wien) 88:1-9, 1987

28. Thompson JB, Mason TH, Haines GL, Cassidy RJ: Surgical management of diastatic linear skull fractures in infants. J Neurosurg 39:493-497, 1973

29. Trotter WBL: The scalp, skull and brain, in Choyce CC, Beattie JM (eds): A System of Surgery. New York: PB Hoeber, 1923, Vol 3, pp 536-565

30. von Winiwarter A: Uber einen Fall von Defect des knöchernen Schadeldaches in Folge einer wahrend des ersten Lebensjahres erlittenen Verletzung. Arch Klin Chir 31:135-147, 1885

31. Weinlechner J: Ueber die im Kindesalter vorkommenden subeutanen Schadelfissuren und die damit zusammenhangenden Schadellticken mit anlagerndem Gehirn und falschen Meningocelen. Jahrb Kinderheilk 18:367-387, 1882
32. Yamashita K, Hayashi J, Tsunoda T: Howship-Romberg sign caused by an obturator granuloma. Am J Surg 187:775-776, 2004

\section{Author Contributions}

Conception and design: Bir. Acquisition of data: Bir. Drafting the article: Bir. Reviewed submitted version of manuscript: all authors. Approved the final version of the manuscript on behalf of all authors: Nanda.

\section{Correspondence}

Anil Nanda, Department of Neurosurgery, LSU Health Shreveport, 1501 Kings Hwy., Shreveport, LA 71130-3932. email: ananda@1suhsc.edu. 